\title{
"Sim, Eu Ouvi o que Eles Disseram": o Diálogo como Movimento de Ir até Onde o Outro Está
}

\author{
"Yes, I Heard What They Said": the Dialogue as the Movement of Going to \\ Where the Other Is
}

Raquel Milani* $^{*}$

\begin{abstract}
Resumo
O texto trata de uma pesquisa realizada sobre a aprendizagem do diálogo por futuros professores de matemática. Os objetivos da investigação foram compreender tal processo de aprendizagem e teorizar sobre o diálogo. Baseada nas ideias teóricas de Alrø e Skovsmose a respeito do diálogo em educação matemática, uma disciplina de estágio supervisionado foi desenvolvida para ser o contexto da produção dos dados. A prática de diálogo dos futuros professores foi acompanhada, e episódios de tal prática constituíram um primeiro nível de dados. Em momentos de orientação e imaginação pedagógica, os licenciandos refletiram sobre tais episódios e suas falas constituíram dados sobre dados. Um episódio mostrando a tentativa de uma estagiária de colocar em ação o diálogo com seus alunos é apresentado. Elementos essenciais do diálogo, como escuta ativa, estranhamento e descentramento, são enfatizados. Uma interpretação de diálogo baseada no movimento de ir até onde o outro está é discutida.
\end{abstract}

Palavras-chave: Diálogo. Aprendizagem do Diálogo. Formação de Professores de Matemática. Dados sobre Dados. Imaginação Pedagógica.

\begin{abstract}
This text concerns a research on the process of dialogue learning by prospective mathematics teachers. The aim was to understand such learning process and theorize about the dialogue. Based on theoretical ideas about the dialogue from Alrø and Skovsmose, we designed a teaching practice course on mathematics as the context of data production. The dialogue practice of the prospective teachers was followed and the episodes from those practices constituted a first level of data. In moments of supervision and pedagogical imagination, the prospective teachers reflected on such episodes and their conversation constituted data about data. An episode about a prospective teacher's attempt to put the dialogue in action with her students is presented. Essential elements of dialogue such as active listening, estrangement, and decentring are emphasized. We discuss an interpretation for dialogue based on the movement of going where the other is.
\end{abstract}

Keywords: Dialogue. Dialogue Learning. Mathematics Teacher Education. Data about Data. Pedagogical Imagination

\section{A respeito de uma prática de diálogo}

\footnotetext{
* Doutora em Educação Matemática pela Universidade Estadual Paulista (UNESP). Professora Adjunta da Universidade Federal do Rio Grande (FURG), Santo Antônio da Patrulha, Rio Grande do Sul, Brasil. Endereço para correspondência: Rua Barão do Caí, 125, Cidade Alta, 95.500-000, Santo Antônio da Patrulha, Rio Grande do Sul, Brasil.E-mail: raqmilani@gmail.com.
} 
Era noite de quinta-feira em Caxias do Sul. Isabela saiu de seu trabalho em uma empresa da cidade e foi até a escola para realizar mais uma aula de seu estágio. Naquele ano, ela se formaria professora de matemática e confiava a esse estágio a decisão de iniciar ou não a carreira docente, já que as experiências anteriores haviam sido desgostosas e fizeram Isabela acreditar que não seria professora. Em seu campo de estágio, Isabela estava trabalhando com os alunos sobre o conjunto dos números complexos. Na aula dessa noite, eu, sua supervisora de estágio, estaria presente. Quando Isabela e eu entramos na sala de aula, os alunos começaram a se acomodar em seus lugares. Sentei-me ao fundo. A chamada foi feita e Isabela iniciou sua fala, enquanto alguns alunos conversavam. As conversas paralelas eram bem frequentes nas aulas, tanto entre os alunos da sala quanto entre pessoas fora da escola e alunos de outras turmas.

Para essa aula, Isabela havia planejado introduzir e explorar o plano de Argand-Gauss e iniciar o estudo das operações com números complexos. A motivação escolhida pela estagiária, para trabalhar com seus alunos sobre essa temática, foi a exploração da relação entre gráficos de funções quadráticas que não interceptavam o eixo horizontal do plano cartesiano e as raízes dessas funções. Em aulas anteriores a dessa noite, Isabela havia discutido com os alunos a respeito dessa relação, evidenciando os números não reais que surgiram nessa atividade.

Em uma fala repleta de perguntas, Isabela iniciou a aula convidando os alunos a dizerem exemplos de números reais que poderiam ser marcados no eixo horizontal de um plano cartesiano desenhado no quadro-negro. Pelo menos um exemplo de cada conjunto numérico foi marcado. Chegaria a hora de pensar nos números complexos, cuja forma algébrica, bem como a unidade imaginária, fora estudada nas aulas anteriores.

Isabela: E agora, um complexo? Como eu poderia marcar um complexo?

Essas duas perguntas deram início a um dos episódios da prática de diálogo de Isabela. Tal prática fez parte da produção de dados da pesquisa de doutorado que realizei. Antes, porém, de apresentar o diálogo de Isabela e seus alunos, é preciso contextualizar essa pesquisa.

\section{Uma pesquisa sobre a aprendizagem do diálogo em educação matemática}

Desde que iniciei minha carreira docente, após o mestrado em educação matemática, pensar sobre diálogo como meio para promover aprendizagem se constituiu uma atividade corriqueira. Do mestrado, era frequente lembrar os momentos em que auxiliava alunos de 
graduação, em seus estudos de matemática, ao tentar entender o que eles estavam pensando, fazendo perguntas e ouvindo-os. Nessa etapa de formação, explorei o ouvir e o perguntar. A máxima de Roberto Ribeiro Baldino, orientador da dissertação, “ensina-se ouvindo; aprendese falando", se concretizava como uma prática difícil, mas com muito sentido. A essas aprendizagens, agreguei novos elementos para a reflexão sobre diálogo vindos de minha prática docente na Educação Básica e na formação de professores. Percebia, por exemplo, na orientação de futuros professores nas disciplinas de estágio, que, muitos deles, concordavam sobre a importância de ouvir o que os alunos têm a dizer sobre o que se está estudando em matemática e de tentar compreendê-los. Em suas aulas nas escolas, no contexto do estágio supervisionado, no entanto, a grande maioria não colocava em prática essas ações. Não fora simples, no mestrado, aprender a ouvir e perguntar, elementos esses importantes do diálogo. Mas, e no curso de formação inicial de professores? O que eu poderia fazer para que os licenciandos desenvolvessem ações relacionadas ao diálogo junto a seus alunos? O que dizer do processo de aprender a dialogar?

Com essa intenção e com as aprendizagens e as reflexões advindas do mestrado e de minha posterior prática docente, iniciei os estudos de doutorado a respeito da aprendizagem do diálogo por futuros professores de matemática, no contexto do estágio supervisionado (MILANI, 2015). Como objetivos de cunho teórico, almejava compreender o processo de aprender a dialogar e elaborar uma interpretação para o diálogo em educação matemática condizente a esse processo. Do ponto de vista pragmático, objetivava propor ações que auxiliassem os futuros professores na aprendizagem do diálogo.

\subsection{Sobre o diálogo antes da produção dos dados}

Se considerarmos um contexto amplo, relativo à interação entre professor e alunos nas aulas de matemática, podemos identificar diferentes padrões de comunicação, como por exemplo, diálogo, discurso expositivo do professor, padrão sanduíche e adivinhação. No padrão sanduíche, a fala dos alunos é sanduichada pela do professor. Geralmente ele faz uma pergunta do tipo fatual, a qual solicita que os estudantes evoquem definições ou fatos matemáticos específicos, os alunos fornecem a resposta e, por fim, o professor avalia o que foi respondido. As perguntas são feitas pelo professor e as respostas já são conhecidas de antemão. Esse padrão é quase um monólogo, pois os alunos apenas recheiam o discurso do professor. Algumas vezes, eles não respondem o que ele estava esperando e, aí, começa um 
jogo de adivinhação, em que a preocupação é tentar adivinhar o que o professor quer como resposta, característica essa do padrão adivinhação (ALRØ; SKOVSMOSE, 2004).

Essas formas de comunicação, estabelecidas nas aulas, influenciam as qualidades da aprendizagem de matemática (ALRØ; SKOVSMOSE, 2004). Não são todas essas formas que possibilitam que os alunos se expressem conforme suas próprias ideias. Um exemplo é o padrão em que a fala do professor é predominante. Quando se considera, no entanto, uma interação mais aberta, muitas ações intimamente relacionadas ao diálogo ganham evidência.

Diversas pesquisas tratam de ações importantes como, por exemplo, ouvir o raciocínio dos alunos, elaborar perguntas de modo a contribuir com sua aprendizagem e convidá-los a falar sobre os conceitos. Ball e Fornazi (2009) enfatizam, entre outros aspectos, a importância de fazer o aluno explicitar suas ideias para que o professor conheça-as e use-as para o desenvolvimento das atividades nas aulas, bem como para que os alunos possam, juntos, construir conhecimentos matemáticos.

Para Wallach e Even (2005), não se trata de existir um momento específico da aula para conhecer e avaliar as ideias dos alunos, mas, sim, de incorporar essas ações em toda a prática pedagógica. Segundo esses autores, isso pode ser feito, por exemplo, na escuta atenta às falas dos alunos ao resolver um problema. Ouvir os alunos é uma ferramenta poderosa para compreender o que eles dizem, mostram, sentem e fazem nas tarefas matemáticas.

Especificamente sobre a ação de perguntar, Moyer e Milewicz (2002) sugerem que quando os futuros professores se envolvem em práticas como a de entrevistar uma criança, tendo algumas perguntas previamente planejadas, e de refletir sobre essa interação, eles podem reconhecer os tipos de perguntas e estratégias que são mais apropriadas e efetivas em certas situações.

Almeida e Fernandes (2010), ao analisar o padrão de interação e o tipo de questionamento de futuros professores de matemática, perceberam que eles, ao longo de sua prática docente desenvolvida com momentos de reflexão, foram ampliando o tempo de espera pelas respostas dos alunos. Os autores reforçam a importância da reflexão com orientação para que se possa aprimorar certas ações, como o perguntar e o esperar por respostas.

Chapin, Connor e Anderson (2009, p. 6) afirmam que o diálogo pode fornecer "acess to ideas, relationships among those ideas, strategies, procedures, facts, mathematical history, and more". Na discussão desses aspectos, os alunos podem ser encorajados a "treat one another as equal partners in thinking, conjecturing, exploring, and sharing ideas”.

Da literatura destacada anteriormente sobre ações relacionadas ao diálogo e da experiência em minha prática, sabia da dificuldade de professores em início de carreira e de 
futuros professores de ouvir seus alunos, levar em consideração diferentes perspectivas, interpretar diferentes respostas, formular perguntas e, de modo geral, interagir mais abertamente com os alunos. Sabia, também, da importância do diálogo para a aprendizagem. Perante tal cenário, acreditava que algumas ações em favor da aprendizagem do diálogo poderiam ser realizadas na formação de professores. Tais ações seriam colocadas em prática na produção de dados que me propunha a fazer na investigação de doutorado.

Como referencial teórico inicial, baseei-me na concepção de diálogo para Alrø e Skovsmose (2004) no contexto da educação matemática crítica. Os autores caracterizam, empiricamente, o diálogo entre professor e alunos e entre alunos em termos de atos dialógicos que constituem o Modelo de Cooperação Investigativa: estabelecer contato, perceber, reconhecer, posicionar-se, pensar alto, reformular, desafiar e avaliar.

Os autores elegeram tais atos ao acompanhar alunos e professores interagindo em cenários para investigação referentes à matemática, realidade e semirrealidade. Esses cenários são ambientes de aprendizagem criados para realizar investigações e que convidam os alunos a formularem questões, procurarem explicações e fazerem descobertas. Eles têm liberdade para escolher o caminho a ser percorrido e agem conforme suas decisões.

Uma vez que se engajem no trabalho, o professor não tem como antecipar o que os alunos descobrirão em sua investigação. Um trabalho como esse é caracterizado, portanto, por um alto grau de imprevisibilidade. Uma mesma atividade pode levar a diferentes desfechos, dependendo do nível de ensino em que é desenvolvida. Não se busca resultados genuínos, mas, sim, que os alunos façam suas próprias descobertas. Os participantes, geralmente, trabalham em grupos e pretende-se que se envolvam de forma ativa e cooperativa. Um cenário para investigação é planejado para fornecer significado ao que os alunos estão produzindo na atividade (SKOVSMOSE, 2011).

No que se refere ao contexto teórico do diálogo, Alrø e Skovsmose (2004) o relacionam à realização de uma investigação, correr riscos e promover igualdade. O primeiro elemento foi explicitado, anteriormente, na descrição de um cenário para investigação. A respeito de correr riscos, os autores afirmam que os rumos de um diálogo são imprevisíveis. Acreditar que, nesse contexto, novas perspectivas possam ser criadas, implica em não conhecer de antemão que ideias são essas.

Quando se deseja saber o que o outro pensa, pode-se desconfiar de algo, mas não se tem a certeza do que o outro vai responder. São as diversas respostas e participações verbais e não verbais dos participantes que alimentam e dão vida ao diálogo. Aprender e investigar em um cenário dialógico envolve, portanto, correr riscos. A imprevisibilidade, nesse contexto, 
está associada ao desafio de tentar novas possibilidades, o que gera oportunidades de aprendizagem.

Quando se considera o conhecimento que professor e alunos têm a respeito de um conteúdo específico, uma relação assimétrica entre eles é estabelecida: o professor tem mais conhecimento científico sobre esse conteúdo que os alunos. O diálogo, porém, não pode ser influenciado por essa relação. Professor e alunos estão em contato, e o que se deseja é que haja uma relação interpessoal igualitária. Assim, promover a igualdade no diálogo não significa negar a diversidade e as diferenças, mas, sim, saber lidar com as mesmas, de forma justa. O professor pode convidar os alunos para participarem de um diálogo, e para que ele ocorra os alunos devem aceitar esse convite.

Então, o princípio da igualdade tem a ver com o convite ao diálogo. Para promover a igualdade, e por consequência a aprendizagem, é preciso que se tente agir de acordo com três características: coerência, empatia e consideração. Ser coerente significa ser transparente e verdadeiro em relação ao que se pensa e faz. A empatia do professor aparece quando ele tenta entender o ponto de vista dos alunos, coloca-se no lugar do outro e tem consciência da perspectiva do outro. A consideração está relacionada a aceitar e respeitar o outro com quem se dialoga, sem a intenção de mudá-lo. No diálogo, professor e alunos têm direito à fala e a ser escutados. As diferenças e a diversidade ao agir e pensar são respeitadas.

Um elemento importante do diálogo, relacionado a diversos atos dialógicos, é a escuta ativa, o que significa "asking questions and giving non-verbal support while finding out what the other is getting at" (ALRØ; SKOVSMOSE, 2004, p. 62). Um olhar atento, uma expressão facial que represente interesse pela fala do outro e um balançar afirmativo da cabeça acolhem os discursos dos alunos. Isso representa um incentivo para que continuem seu trabalho. Perguntas de caráter investigativo, hipotético ou que buscam uma confirmação, e uma atenção especial ao que o aluno diz, auxiliam o professor a compreender o que ele está pensando.

\subsection{Um contexto possível para a aprendizagem do diálogo}

Tomando como inspirações os conceitos teóricos apresentados até aqui, e as aprendizagens de minha prática docente, uma disciplina de estágio supervisionado em matemática foi planejada com o objetivo de promover um encontro entre os estagiários e o conceito de diálogo. Tal disciplina fazia parte do currículo do curso de Licenciatura em Matemática da universidade da qual eu estava afastada para realizar o doutorado. À época, o estágio era organizado para ser realizado em 420 horas distribuídas em quatro disciplinas, a 
partir da segunda metade do curso. O Estágio I perfazia 60 horas e tratava da elaboração de uma proposta educacional para o ensino de matemática, a partir da caracterização do contexto escolar e de referenciais da área. As três disciplinas seguintes de estágio (II, III e IV) perfaziam 120 horas cada, e previam a atuação docente do licenciando em matemática envolvendo diagnóstico, planejamento, execução e avaliação, em classes do Ensino Fundamental (etapa II), Ensino Médio (etapa III), e em ambiente de aprendizagem diferente desses últimos (etapa IV).

A produção dos dados da pesquisa ocorreu na disciplina de estágio supervisionado III. Dentro da proposta do estágio, descrita anteriormente, essa disciplina teve momentos de reflexão sobre tópicos de educação matemática, observação de aulas de matemática do Ensino Médio, planejamento de aulas e prática docente em salas de aula de matemática desse mesmo nível da Educação Básica. Todos esses momentos tiveram um foco muito específico: o diálogo como forma de comunicação entre professor e alunos para promover aprendizagem.

Por isso, a professora responsável pela disciplina, o orientador desta pesquisa - Ole Skovsmose - e eu elaboramos atividades de diálogo de caráter investigativo, reflexivo e de planejamento. O objetivo dessas atividades era fazer com que os licenciandos pudessem experimentar o diálogo em atividades investigativas, reconhecer-se como pessoas em diálogo, analisar os elementos desse diálogo e seus benefícios à aprendizagem de matemática, e imaginar-se professores em diálogo com seus alunos.

Como parte fundamental dessa disciplina, os futuros professores planejaram e executaram aulas de matemática para turmas do Ensino Médio, tendo como guia as discussões e atividades realizadas sobre diálogo. Esse processo foi orientado pela professora da disciplina e por mim. Éramos chamadas de professoras pelos licenciandos participantes da pesquisa. Nesse contexto, portanto, assumi a posição de practitioner-researcher (JARVIS, 1999), ou seja, o profissional que desenvolve pesquisa sobre sua própria prática e que, portanto, sabe o que funciona em seu trabalho, sente-se confortável em relação aos conhecimentos, às habilidades e às atitudes vindos da sua prática, e sabe quais os problemas existentes a serem investigados.

Em um diário, eu registrava e relatava o que ocorria nos encontros com os estagiários na universidade e nas práticas docentes nas escolas. Nele, eu escrevia informações importantes que poderiam me ajudar a refletir sobre o tema da pesquisa. Os instrumentos de geração de informações foram de dois tipos: registros escritos e áudio. Os registros escritos referem-se às produções escritas dos futuros professores: descrição de uma boa aula de matemática e do que é diálogo, avaliação sobre uma atividade investigativa, planejamento de 
uma atividade mediada pelo diálogo, planejamento das aulas nas escolas e relato de experiência sobre o estágio de docência.

Já os eventos que tiveram o áudio gravado foram: apresentação inicial dos estagiários no primeiro encontro na Universidade, atividades investigativas, apresentação do planejamento de uma atividade mediada pelo diálogo, atividades de diálogo de caráter reflexivo, apresentação sobre o período de observação do campo de estágio, aulas dos estagiários nas escolas, momentos de orientação das professoras supervisoras com os futuros professores e apresentação sobre seu período de docência.

Nem todos os áudios foram transcritos e nem todas as informações registradas nos áudios e produções escritas dos estagiários foram utilizados na etapa de análise dos dados da pesquisa. Entre todas as informações que produzimos (futuros professores e professoras supervisoras), algumas se sobressaíram, porque diziam respeito a como o diálogo era entendido pelos participantes da pesquisa (e nesse grupo eu me incluía) e como ele poderia ser e, de fato, foi colocado em ação pelos estagiários.

O destaque dado a essas informações aconteceu ao longo da etapa de produção dos dados, e elas permaneceram em minha mente durante o momento de reflexão e análise dos dados. No final da minha estada no campo empírico, interpretei esse destaque como sendo um sinal do que constituiria o conjunto de dados da pesquisa. Assim, nem todas as informações produzidas foram chamadas de dados. Alguns dados são recortes feitos de registros escritos produzidos pelos estagiários ou algumas de suas falas. Outros, referem-se a trechos de interação entre os participantes na universidade, entre um estagiário e seus alunos na escola ou entre um estagiário e eu, em momentos de orientação. Esses trechos de interação foram chamados de episódios e, juntamente com algumas produções escritas dos licenciandos, constituíram os dados da pesquisa.

Ao redigir os episódios relativos aos trechos selecionados das interações dos futuros professores, tentava falar sobre eles a partir de minhas próprias concepções e ousava sugerir algumas interpretações e conclusões. É nessa linha de pensamento que Creswell (2007, p. 27) diz que os pesquisadores qualitativos "fazem uma interpretação do que encontram, moldada pelas experiências próprias e pela formação do pesquisador”. As primeiras reflexões que fiz em relação aos dados traziam o conhecimento de minha prática e ideias teóricas iniciais sobre diálogo. Tratava-se de uma teoria enraizada nos dados, e que dizia respeito àquelas pessoas participantes da pesquisa. Precisava, primeiramente, compreender seus significados e refletir sobre eles, seguindo uma orientação naturalista ou interpretativa (DENZIN; LINCOLN, 2006), para que depois pudesse avançar para outro tipo de teoria. Portanto, ao final da 
pesquisa, extrapolei o campo empírico e as reflexões específicas para, então, poder fazer afirmações sobre o aprender a dialogar e o próprio conceito de diálogo, em um movimento de generalização.

Para discutir sobre a tentativa de colocar o diálogo em ação, trago, na próxima seção deste texto, um episódio da prática docente de Isabela, uma estagiária que havia participado com afinco das discussões e atividades sobre diálogo realizadas na disciplina, e havia aceitado ao convite de participar da pesquisa.

Uma vez que a prática dos licenciandos foi guiada pelas discussões que tivemos na disciplina sobre diálogo, chamei-as de práticas de diálogo. Refletir sobre a prática de Isabela, assim como de outros futuros professores que participaram da pesquisa, forneceria indícios do que ocorre no processo de aprender a dialogar, e isso auxiliaria a discutir sobre o que é o diálogo.

Vale lembrar, como foi dito no início deste texto, que Isabela confiava a esse estágio a decisão de iniciar ou não a carreira docente, uma vez que ela não gostara de sua experiência no estágio anterior (em uma turma do Ensino Fundamental). Nas palavras dela: "os alunos não me ouviam”. Em um de seus relatos, ela disse que chegava em casa, depois da aula na escola, e chorava para o namorado. Tinha dor de estômago quando chegava perto do horário da aula. "A comida do almoço não descia" (ISABELA, 2012). Apesar de seu desgosto pela experiência anterior, estava disposta a tentar mais uma vez, tendo em vista que faltavam poucas disciplinas para terminar o curso. Desse modo, participou de todas as atividades de diálogo propostas e era sempre muito franca, ao compartilhar com as professoras e colegas, suas aflições e ideias em relação à prática docente.

É necessário fazer alguns esclarecimentos antes de apresentar o episódio. A transcrição do áudio teve como base o que dois gravadores registraram: um deles estava junto à Isabela e o outro estava comigo, ao fundo da sala de aula. Algumas expressões da transcrição estão em itálico para mostrar a ênfase dada pela pessoa que as falou. Quando escrevo alunos, não me refiro à fala de todos os alunos da turma, mas, sim, de um grupo deles que não é sempre o mesmo em cada aparição. O mesmo é válido para aluno. Em alguns momentos do episódio, houve conversas entre alguns alunos enquanto Isabela falava com a turma, e quando algum aluno se pronunciava. Assim, nem sempre havia silêncio por parte daqueles que não estavam envolvidos em determinada parte do diálogo. Naquela aula eu assumi o papel de supervisora e pesquisadora.

Ressalto, ainda, que uso a palavra diálogo com a liberdade de poder teorizar sobre essa forma de interação. Além disso, quando faço referência ao diálogo de Isabela com seus 
alunos, estou me referindo a sua interação em sala de aula, que foi planejada e pautada de acordo com o que estudamos na disciplina de estágio sobre esse conceito. A interação de Isabela com os alunos refere-se à sua tentativa de dialogar em suas aulas de matemática.

\section{3 "Desculpa, eu não te entendi”: a prática de diálogo de Isabela}

As aulas de Isabela eram repletas de perguntas que buscavam a participação dos alunos para sugerir ideias, confirmar fatos e fornecer respostas específicas. Quando tais respostas eram as esperadas por ela e, portanto, corretas, segundo seu modo de pensar, Isabela sabia como lidar: aceitava as respostas e as valorizava, incorporando-as em seu discurso seguinte. Quando a estagiária não esperava alguma resposta dos alunos, ela reagia de modo diferente. É o que apresento na continuidade deste artigo.

Retomando o que eu narrava na primeira seção deste texto, Isabela e os alunos estavam estudando sobre o conjunto dos números complexos. Nas aulas anteriores, os alunos já haviam realizado uma atividade sobre equações de segundo grau, tanto com raízes reais quanto não reais. $\mathrm{Na}$ aula de que trata esse episódio, Isabela e os alunos estavam marcando alguns números reais no eixo $O x$ do plano cartesiano, e chegava a hora de representar os números complexos.

Isabela: E agora um complexo? Como eu poderia marcar um complexo?

Aluno: Qualquer um?

Aluno: $\sqrt{3}$.

Aluno: Raiz de menos (pausa) 3.

Isabela: Raiz... (pausa) Desculpa, eu não te entendi (dirigindo-se a algum aluno). (pausa) Um número complexo da forma $a+b i$ ? Eu tenho $1+2 i$. Onde eu poderia marcar esse número? (pausa) Alguém tem alguma ideia? (pausa) Alguém tem alguma ideia de como eu poderia marcar?

Aluno: -2 .

(pausa)

Isabela: $O$ que a gente viu também? Que um número complexo $1+2 i$ é composto de duas partes, né? Uma parte real e outra parte que é...?

Aluno: Imaginária.

Isabela: Imaginária. Quem é nossa parte real?

Alunos: É o 1.

Isabela: É o 1. Tá, então nosso 1 tá aqui (marca no eixo horizontal do plano). Quem é a nossa parte imaginária?

Alunos: $2 i$.

Isabela: $2 i$. Onde eu poderia marcar esse $2 i$ ? (Isabela afirma que a parte imaginária de $1+2 i$ é $2 i$, o que não é verdade segundo a teoria do conjunto dos números complexos).

Alunos: -2 .

(pausa)

Isabela: Mais 2 i (escrevendo no quadro). O que significa o i mesmo? (pausa) Quem é o nosso $i$ ? Todo mundo esqueceu?

Aluno: -1 . 
Isabela: (estranhando) -1? (agora rindo) Quem é a nossa unidade imaginária? Quem a gente estabeleceu como nossa unidade imaginária?

Alunos: -1.

Aluno: Raiz de -1 .

Isabela: Ahhh... raiz de -1 .

Aluno: Mas é-1!

Isabela: Tá (rindo). Mas agora onde vocês acham que eu poderia marcar? (EPISÓDIO DO 2, 2012).

Isabela não obteve respostas dos alunos para a última pergunta que elaborou. Por isso, nesse momento, ela introduziu o plano de Argand-Gauss, mostrando o eixo real e o imaginário. Quando ela perguntou, novamente, sobre como marcar o número $1+2 i$ nesse plano, os alunos responderam 1 para o eixo horizontal e -2 para o eixo imaginário. Novamente, - 2 apareceu como resposta. O diálogo é desviado por uma pergunta de uma aluna, que havia faltado nas aulas anteriores e, ao retomar, Isabela diz como os números complexos são localizados no plano de Argand-Gauss.

Para quem ler o episódio do - 2, sem ter estado presente na aula ou sem ter conversado com Isabela sobre a aula, pode parecer que ela havia ignorado as respostas dos alunos, especialmente quando respondiam - 2. Uma exceção poderia ser quando ela disse: "Desculpa. Eu não te entendi". Mesmo eu estando presente, e vendo a tentativa de Isabela de dialogar com os alunos, minhas impressões configuram um olhar externo à sua prática. $\mathrm{O}$ que diz Isabela sobre o que fez e pensou? Como ela enxerga sua prática de diálogo? Os dados constituídos no episódio do - 2 não são suficientes para responder a essas perguntas. Saber dessas respostas seria fundamental para compreender o diálogo em ação de Isabela, e poder dizer sobre o processo de aprender a dialogar. Portanto, novos dados foram produzidos a partir dos já existentes (no caso, o episódio do - 2). Trata-se de dados sobre dados, ou seja, uma reflexão e uma clarificação dos dados iniciais.

Após a aula em que o episódio do - 2 ocorreu, Isabela e eu nos reunimos para refletir e compreender o que havia acontecido. O episódio foi retomado, quando pergunto a Isabela se ela havia escutado seus alunos respondendo - 2 para seus questionamentos sobre a marcação do número $1+2 i$ no plano.

Eu ouvi o-2 e aí eu não sei se eu perguntei o porquê do -2, mas eu escrevi (no quadro) "1 +2 ..." e perguntei "quem que era o i?". Ali eu tentei responder sobre aquele -2 . Eu acho que esse -2 apareceu por causa do -1 , raiz de -1 . Eu acho que foi por causa disso, $e$ ai eu tentei reescrever lá "tá, mas o que é $1+2 i$ ?". E dai eu reescrevi o raiz de -1 (no lugar de i) para mostrar que não era (-1). 2, e sim $\sqrt{-1} .2$, que era o $i$. Ali eu tentei mostrar (ISABELA, 2012). 
Isabela escutou a resposta -2 e a levou em consideração. Falamos, então, da importância de acolher as respostas dos alunos no diálogo. Isabela afirmou, ainda, que não perguntou o porquê da resposta -2 para saber se a justificativa deles coincidia com a sua.

Raquel: Mas isso é uma prática, um treino. Um bom primeiro passo foi tu tentar imaginar o que ele pensou.

Isabela: Sim, isso eu fiz (Isabela mostra-se feliz com isso).

Raquel: Perfeito (as duas riem). Agora a gente pode explicitar isso, porque de repente outros estão pensando que é -2 e não entenderam por que não é -2 .

Isabela: Hmmm. Porque eu fiz aquilo (substituição de i por $\sqrt{-1}$ ) bem no cantinho, do lado do gráfico, mas não ficou claro.

Raquel: Ficou pra ti aquilo ali.

Isabela: É (DADOS SOBRE DADOS, 2012).

Nesse momento de reflexão e orientação, Isabela explicou seu ponto de vista sobre o episódio do -2. Após cada resposta - 2 dada pelos alunos, Isabela fazia uma pausa em seu discurso. De alguma forma, ela estava considerando tal resposta. Nessa pausa, provavelmente pensava sobre tal enunciação. De onde essa resposta veio? O que ela significa? Cabe reforçar que, sem os dados sobre dados, seria possível afirmar que Isabela havia ignorado a resposta dos alunos. Ao contrário disso, no momento de reflexão e orientação, Isabela afirmou que ouviu os alunos responderem -2 e pensou em uma justificativa para produzirem tal resposta: consideraram o número $i$ como -1 e o multiplicaram por 2. Ela ainda tentou mostrar tal justificativa ao perguntar pelo significado da unidade imaginária, considerando o número $1+2 i$. Segundo Isabela, sua explicação foi registrada "bem no cantinho" do quadro-negro, o que não ficou claro para a turma, segundo ela, e nem para mim que lá estava. As pausas, agora, haviam ficado claras. Portanto, Isabela escutou a resposta dos alunos, levou-a em consideração ao refletir sobre ela, elaborou uma justificativa possível para os alunos terem pensado dessa maneira e tornou-a explícita de algum modo.

Partindo do que Isabela fizera em sua aula, em termos de diálogo, nós salientamos o que ela não havia realizado: não perguntou aos alunos como eles pensaram para responder - 2 e não explicitou à turma inteira tal pensamento e justificativa. Esse era o panorama real explicitado no momento da orientação, ou seja, o que foi feito e o que não foi feito por Isabela. Tendo isso clarificado, começamos a vislumbrar o que poderia ser.

Nesse momento, teve início o processo de imaginação pedagógica, criando-se possibilidades de ações futuras para a prática de Isabela, em especial para sua prática de diálogo. Imaginar o que pode acontecer não é uma tarefa totalmente livre. Pode-se, sim, imaginar diversas possibilidades de ação, mas essas são fortemente influenciadas pelas intenções das pessoas envolvidas nesse processo, e são criadas a partir do que se tem como 
situação real. Esse processo, com liberdade para criar e repleto de reflexão, é de grande valia para a formação do professor, uma vez que revela possibilidades para as práticas educacionais. "The existence of an imagination that describes alternatives to an actual situation makes a difference. By this imagination, experienced necessities could be reduced to contingencies - they could be different" (SKOVSMOSE, 2014, p. 124, grifo do autor). As situações que se apresentavam para Isabela em sua prática poderiam ser repensadas e não aceitas como naturais. Considerar, juntamente com Isabela, o que ela não realizou e o que poderia ainda ser feito, gerou a oportunidade de pensarmos em possibilidades para sua prática de diálogo. Trata-se de uma imaginação pedagógica entre estagiária e supervisora.

Assim, além de imaginar o que o aluno pensou para fornecer determinada resposta, o professor pode solicitar que ele explique à turma inteira esse pensamento e, também, fazer perguntas para melhor compreender esse modo de pensar, uma vez que isso gerou respostas inesperadas para o professor. De certa forma, Isabela avançou nesse aspecto em suas aulas seguintes.

\section{Elementos essenciais do diálogo}

A prática de diálogo de Isabela e o momento de reflexão e orientação fizeram com que eu lembrasse de algumas ideias da minha prática como formadora de professores e de algumas experiências que tive no mestrado. Levando isso em conta, e inspirada pelos conceitos teóricos sobre diálogo e interação, elegi alguns elementos essenciais do diálogo: escuta ativa (ALRØ; SKOVSMOSE, 2004), estranhamento (LINS, 2004) e descentramento (OLIVEIRA, 2012). A tentativa de Isabela de colocar o diálogo em ação com seus alunos pôde ser lida (por mim) como um esforço de exercitar esses elementos.

Um contato entre Isabela e seus alunos foi estabelecido no diálogo. Alrø e Skovsmose (2004, p. 101) definem o ato dialógico de estabelecer contato como "being present and paying attention to each other and to the contributions of one another in a relation of mutual respect, responsability and confidence". O olhar recíproco e atento de Isabela e seus alunos e a atenção dispensada por eles marca o início desse contato. Vale ressaltar que Isabela procurava esses olhares fixos a ela como incentivo para continuar o diálogo. Para que esse contato se mantivesse, foi preciso realizar um tipo especial de escuta às contribuições dos alunos. Não bastava simplesmente escutá-los, podendo, assim, ignorar essas respostas. Mais do que escutar, Isabela deu atenção ao que foi dito, afirmando, em uma vez, que não havia entendido a ideia dos alunos (“desculpa, eu não te entendi”) e, ao longo do diálogo, tentando 
compreender de que lugar (cognitivo) as respostas estavam vindo (ação representada pelas pausas e confirmada no momento de orientação). Essa atenção e escuta especial está relacionada ao que os autores antes citados chamam de escuta ativa, ou seja, uma escuta atenta ao que o outro diz, um esforço de compreendê-lo, um apoio não verbal e um perguntar investigativo do pensamento do aluno.

Relações podem ser estabelecidas entre as ideias de Alrø e Skovsmose (2004) e a teoria sobre interação de Lins (1999) em termos de produção de significados. Saber do que o outro diz é fundamental na interação, o que pode ser ilustrado, imaginando-se um professor falando a seu aluno:

Não sei como você é; preciso saber. Não sei também onde você está (sei apenas que está em algum lugar); preciso saber onde você está para que eu possa ir até lá falar com você e para que possamos nos entender, e negociar um projeto no qual eu gostaria que estivesse presente a perspectiva de você ir a lugares novos (LINS, 1999, p. 85).

A expressão onde está não é considerada por Lins como lugar físico ou algum estágio de desenvolvimento intelectual, mas, sim, como legitimidade de significados para a pessoa.

Ao realizar a escuta ativa, o professor pode perceber uma diferença entre o que ele pensa e o que é dito pelo aluno. Nesse caso, um estranhamento pode ocorrer. Algo que não é natural para o professor pode ser explicitado pelo aluno, ou vice-versa, como aconteceu quando Isabela ouviu a resposta - 2. Nesse processo de estranhamento, "o que importa mesmo é que exista de um lado aquele para quem uma coisa é natural - ainda que estranha - e de outro aquele para quem aquilo não pode ser dito" (LINS, 2004, p. 116). O estranhamento faz surgir a diferença, ou seja, dois modos distintos de se pensar, ambos legítimos tendo em vista que foram enunciados segundo certa lógica. Assim, a resposta -2 é válida na lógica dos alunos que a enunciaram, o que não é verdade para a lógica da matemática acadêmica.

A noção de estranhamento trazida por Lins é importante para o conceito de diálogo, pois explicita uma diferença, como antes falado. Perante o estranhamento, o professor pode escolher entre, por exemplo, considerar e explicitar tal diferença ou não. Dependendo de sua atitude, o diálogo pode ser continuado ou interrompido. Quando ele se interessa por tentar entender onde o aluno está, ou seja, de que lugar (cognitivo) o aluno fala, ele ingressa em um processo de descentramento, que significa o "esforço de tornar-se sensível ao estranhamento do outro, de entender do que o outro fala" (OLIVEIRA, 2012, p. 207). No caso do episódio do - 2, o estranhamento foi de Isabela e, então, ela esforça-se para entender do que os alunos 
falam quando enunciam -2 . Tal esforço é caracterizado por um deslocamento de centro ${ }^{1}$.

Quando se busca compreender o que o outro diz, é preciso que se tente olhar para o que foi dito com os olhos de quem o disse. Para tanto, é necessário fazer perguntas para uma melhor compreensão e dar suporte, verbal ou não, à fala do outro. Isso foi considerado no processo de imaginação pedagógica no qual Isabela e eu nos envolvemos, tendo em vista o que a estagiária fez e não fez em sua prática.

Parece que enquanto existir esse estranhamento e certo incômodo com a diferença, o movimento de ir até onde o outro está continua. Nesse movimento, entram em cena a escuta ativa (uma escuta atenta ao que o outro diz, um esforço de compreendê-lo, um apoio não verbal e um perguntar investigativo do pensamento do aluno) e o ato dialógico de reformular, o que significa "repeating what has just been said, maybe slightly different words or tone of voice" (ALRØ; SKOVSMOSE, 2004, p. 108). Reformular uma ideia é importante para que se tenha a confirmação do outro de que se está entendendo o que ele está dizendo. Acho que você está pensando assim e assim. É isso mesmo?

Quando o professor encontra esse lugar (eu entendo como você está pensando), ele compreende a diferença e pode passar a trabalhar com essa nova informação, incluir o pensamento do aluno em seu discurso, compartilhar com a turma a nova ideia e esclarecer que pensamentos distintos estão em jogo. A partir daí, decide-se como seguir no desenvolvimento da aula.

Enquanto houver uma diferença entre modos de pensar, um estranhamento em relação a essa diferença e um movimento de descentramento que busca saber de onde o outro fala, por meio da escuta ativa, o diálogo se mantém em ação. Certamente, não há apenas esses elementos de diálogo, mas os que aqui foram enfatizados tiveram relação muito próxima à prática de Isabela que estava engajada no processo de aprender a dialogar.

\section{Diálogo como movimento}

A partir da reflexão sobre as práticas de diálogo dos futuros professores que participaram da pesquisa, como foi o caso de Isabela, e de inspirações teóricas, como as apresentadas anteriormente, elaborei uma interpretação para o conceito de diálogo.

\footnotetext{
${ }^{1}$ As noções de estranhamento e descentramento que utilizo são inspiradas no que Lins (2004) e Oliveira (2012) dizem, baseados no Modelo dos Campos Semânticos. Os autores falam de diferentes modos de produzir significados e de criar um espaço comunicativo. Nesse texto me refiro a diferentes modos de pensar e ao diálogo.
} 
Diálogo é uma forma de interação entre professor e alunos, engajados em uma atividade de aprendizagem, em que a fala e a escuta ativa são compartilhadas, ideias são discutidas e a compreensão do que o outro diz é fundamental. Essa perspectiva de diálogo em educação matemática tem como base uma postura política que acredita que não pode haver a fala dominada por apenas uma das partes, mas, sim, compartilhada entre as partes.

Trata-se de uma perspectiva que acredita que, com o diálogo, se pode ter aprendizagem. Não há, no entanto, garantia dessa aprendizagem, uma vez que o diálogo é imprevisível e são muitos os fatos que podem ocorrer quando ele está em ação. Diálogo é cercado por incertezas. Pode ser influenciado pelo tipo de atividade desenvolvida e pelas perguntas feitas pelo professor. Não se sabe das intenções dos alunos em certa atividade planejada, e do que irão responder às perguntas realizadas. Dialogar envolve perguntar, por parte do professor e dos alunos também. Perguntas de muitos tipos, mas especialmente dialógicas, que buscam saber o que o outro pensa.

Dialogar é estar com o outro, é mover-se em direção ao outro, ao interessar-se pelo que o outro diz. O aspecto interpessoal da interação está na base do diálogo. Quando professor e alunos dialogam, eles são influenciados uns pelos outros, a ação de um pode ser disparadora da ação do outro, há um encontro e compartilhamento de significados por meio da linguagem na interação. A partir desse encontro, o professor pode aprender como os alunos produzem significados para os objetos de determinada atividade e sobre o desenvolvimento de uma atividade (o que dá certo e o que não dá).

Por sua vez, os alunos podem aprender novos significados e modos de pensar, aqueles do professor ou dos colegas. Na discussão de ideias, opostas ou não, relativas a uma atividade de aprendizagem, não há imposição da perspectiva de uma pessoa sobre a da outra. Não é uma disputa, não há vitorioso e nem perdedor. O que há é movimento, ou seja, a tentativa de compreender o que o outro diz, entrando em ação a escuta ativa, o estranhamento e o descentramento.

A opção pelo diálogo na educação matemática não é neutra. Por que não um discurso exclusivo do professor? Por que o professor dialoga com os alunos? A escolha pelo diálogo, antes de ser uma conduta didática, demonstra uma postura política do professor, como dito anteriormente. É no diálogo, por exemplo, que me movo em direção ao outro para saber do que ele diz. Mas por que é importante saber do que o outro diz e pensa? Eu não estou no mundo sozinha, eu sou e ajo com os outros. No microespaço da aula de matemática, eu, professora, sou com os alunos. No microespaço do curso de Licenciatura em Matemática, eu, professora supervisora, sou com os estagiários. A mim me interessa o que o outro diz, pois é 
assim que, acredito, poderei ir com ele a novos lugares. Não se trata de dar voz aos alunos, expressando poder, dominação: Fale, eu te deixo falar. A escuta ativa não é um exercício de poder, mas, sim, de liberdade: Fale, eu te escuto.

Para finalizar, cerca de um ano e meio depois de Isabela ter encerrado seu estágio e se formado professora de matemática, recebi uma notícia de uma colega da universidade onde realizei a produção dos dados da pesquisa: A Isabela pediu para avisar que ela está lecionando!. Eu estava com a professora da disciplina de estágio no momento em que recebi a notícia. Sorrimos, e nos olhamos. Lembramos da aflição de Isabela ao iniciar seu estágio e de sua aposta nessa experiência para saber se gostaria ou não de seguir a carreira docente. Em especial, o recado de Isabela me fez lembrar da última quinta-feira à noite em que Isabela entrou na sala de aula onde lecionava. Disse aos seus alunos, emocionada, que essa experiência havia mudado a opinião dela sobre lecionar.

Não querendo adotar uma visão romântica dos acontecimentos, mas atentando para o fato de que Isabela não deixava de conversar com seus alunos sobre seus sentimentos relativos a ser professora, um recado como esse me faz confiar, ainda mais, na prática do diálogo, no processo de imaginação pedagógica e numa orientação atenta à prática dos estagiários, como aspectos importantes para a formação de professores.

\section{Agradecimentos}

Pela leitura e sugestões a este texto, agradeço aos colegas Ole Skovsmose, Renato Marcone, Guilherme Henrique Gomes da Silva, Denival Biotto Filho, Ana Carolina Faustino e João Luiz Muzinatti.

\section{Referências}

ALMEIDA, M.; FERNANDES, J. A. A comunicação promovida por futuros professores na aula de Matemática. Zetetiké, Campinas, v. 18, n. 34, p. 109-154, 2010.

ALRØ, H.; SKOVSMOSE, O. Dialogue and Learning in Mathematics Education: intention, reflection, critique. Dordrecht: Kluwer Academic Publishers, 2004. 286 p.

BALL, D. L.; FORNAZI, F. M. The work of teaching and the challenge for teacher education. Journal of Teacher Education, v. 60, n. 5, p. 497-511, nov. 2009.

CHAPIN, S. H.; O'CONNOR, C.; ANDERSON, N. C. Classroom Discussions: using math talk to help students learn, Grades K-6. 2. ed. Sausalito: Math Solutions, 2009. 312 p. 
CRESWELL, J. W. Projeto de pesquisa: métodos qualitativo, quantitativo e misto. Tradução de L. de O. da Rocha. 2. ed. Porto Alegre: Artmed, 2007. 248 p.

DENZIN, N. K.; LINCOLN, Y. S. A disciplina e a prática da pesquisa qualitativa. In: (Org.). O Planejamento da Pesquisa Qualitativa: teorias e abordagens. Porto Alegre: Ed. Artmed, 2006. p. $15-41$.

JARVIS, P. The Practioner-Researcher: developing theory from practice. San Francisco: JosseyBass, 1999. 224 p.

LINS, R. C. Por que discutir teoria do conhecimento é relevante para a Educação Matemática. In: BICUDO, M. A. V. (Org.). Pesquisa em Educação Matemática: concepções \& perspectivas. São Paulo: Ed. UNESP, 1999. p. 75-94.

LINS, R. C. Matemática, monstros, significados e Educação Matemática. In: BICUDO, M. A. V.; BORBA, M. de C. (Org.). Educação Matemática: pesquisa em movimento. São Paulo: Ed. Cortez, 2004. p. 92-120.

MILANI, R. O Processo de Aprender a Dialogar por Futuros Professores de Matemática com Seus Alunos no Estágio Supervisionado. 2015. 238 f. Tese (Doutorado em Educação Matemática) Instituto de Geociências e Ciências Exatas, Universidade Estadual Paulista, Rio Claro, 2015.

MOYER, P. S.; MILEWICZ, E. Learning to question: categories of questioning used by preservice teachers during diagnostic mathematics interviews. Journal of Mathematics Teacher Education, Netherlands, v. 5, n. 4, p. 293-315, 2002.

OLIVEIRA, V. C. A. Sobre as ideias de estranhamento e descentramento na formação de professores de professores de matemática. In: ANGELO, C. L. et al. (Org.). Modelo dos Campos Semânticos e Educação Matemática: 20 anos de história. São Paulo: Ed. Midiograf, 2012. p. 199-216.

SKOVSMOSE, O. An Invitation to Critical Mathematics Education. 1. ed.

Rotterdam/Boston/Taipei: Sense Publishers, 2011. 122 p.

SKOVSMOSE, O. Researching possibilities. In: . (Org.). Critique as uncertainty. Charlotte: Ed. Information Age Publishing, 2014. p. 111-126.

WALLACH, T.; EVEN, R. Hearing students: the complexity of understanding what they are saying, showing, and doing. Journal of Mathematics Teacher Education, Netherlands, v. 8, n. 5, p. 393417,2005 .

Submetido em Junho de 2016. Aprovado em Novembro de 2016. 